\title{
Recorte das características sócio-economicas de travestis prostitutas
}

\author{
Socio-economical characteristics clipping and transvestite \\ prostitutes
}

\author{
Lauro Ricardo de Lima Santos 1 \\ Marcelle Aparecida Junqueira Barros ${ }^{2}$ \\ Maria Cristina de Moura Ferreira ${ }^{3}$ \\ Lúcio Borges de Araújo 4 \\ Carla Denari Giuliani ${ }^{5}$
}

\begin{abstract}
RESUMO
Introdução: A Prostituição como profissão se faz importante principalmente para as travestis. As travestis que são historicamente estigmatizadas e marginalizadas não conseguem, empregos ditos como formais. Materiais e Métodos: Estudo tranversal, descritivo, de caráter quantitativo. A população do estudo foi 46 travestis prostitutas da cidade de Uberlândia-MG. Resultados e Discussões: Foram observados no primeiro momento com os dados socioeconômicos das entrevistadas que em sua maioria são solteiras, têm baixa escolaridade e outros detalhes. Conclusões: A falta de humanização por parte de quem deveria ser referência no cuidado e segurança torna este grupo vulnerável.
\end{abstract}

PALAVRAS-CHAVE: Trabalho sexual. Travestismo. Violência de Gênero. Violência no Trabalho.

\begin{abstract}
Introduction: Prostitution as a profession is especially important for transvestites. Transvestites who are historically stigmatized and marginalized can not, say, formal jobs. Materials and Methods: Crosssectional, descriptive, quantitative study. The study population was 46 transvestite prostitutes from the city of Uberlândia-MG. Results And Discussions: At the first moment, the socioeconomic data of the interviewees were observed, which are mostly single, have low level of schooling and other details. Conclusions: The lack of humanization by
\end{abstract}

\footnotetext{
1 Mestrando e professor da rede particular de ensino técnico de Uberlândia. Programa de Pósgraduação em Saúde Ambiental e Saúde do Trabalhador pela Universidade Federal de Uberlândia, Brasil. E-mail: lauroricls@hotmail.com

2 Pós-doutora. Programa de Pós-graduação em Escola de Enfermagem da Universidade de São Paulo, Brasil. E-mail: marcebarros@yahoo.com.br

${ }^{3}$ Doutora. Programa de Pós-graduação em Escola de Enfermagem da Universidade de São Paulo, Brasil. E-mail: mcmferreira@yahoo.com.br

4 Doutor. Programa de Pós-graduação em Estatística e Experimentação Agronômica pela Escola Superior de Agricultura Luiz de Queiroz, Brasi. E-mail: lucio.araujo@ufu.br

5 Doutora. Programa de Pós-graduação em História e Cultura pela Universidade Federal de Uberlândia, Brasil E-mail: denarigiuliani@bol.com.br
} 
those who should be a reference in care and safety makes this group vulnerable.

KEYWORDS: Sex work. Travestism. Gender-Based Violence. Workplace Violence.

Trabalho, um termo histórico e do ponto de vista etimológico associado ao desagradável, que causa dor, uma forma de castigo, sofrimento e tortura. A palavra trabalho tem origem do latim (tripalium), que era conhecido como um instrumento de tortura que pesava sobre os animais. Assim os nobres, senhores feudais, adotaram o termo para designar aos seus empregados da época, que viam a execução do trabalho com uma forma de castigo (KOWARICK, 1987).

Anteriormente, se o termo trabalho tinha uma finalidade de designar tortura ou algo insatisfatório para o ser humano, hoje a palavra significa toda a energia física ou intelectual empregada para um individuo exercer alguma atividade com finalidade produtiva (LACAZ, 2007).

No Brasil, há a divisão do trabalho em formal e informal. O trabalho dito onde há carteira de trabalho assinada e registrada, oficializadas de acordo com as normas da Consolidação de Leis do Trabalho (CLT), que podem garantir aos trabalhadores diversos direitos, incluindo férias, o $13^{\circ}$ salário e amparos trabalhistas diante de necessidades daquele trabalhador vinculado. Já o trabalho informal significa que o trabalhador não terá vinculo empregatício com nenhuma empresa, isso fazendo com ele não tenha direitos se caso acontecer alguma eventualidade no seu ambiente de trabalho (BASTOS, 2004).

No Brasil, de acordo com a Classificação Brasileira de Ocupações (CBO), a prostituição esta incluída nesta lista, nela descrita como Profissional do Sexo, isso fez com que o Ministério do Trabalho e Emprego reconhecesse a prostituta como trabalhadora, porém já em seu texto afirma que a mesma exerce uma atividade laboral por contra própria, ou seja, de forma informal (BRASIL, 2004). 
A Prostituição como profissão se faz importante para algumas mulheres, homens e principalmente para as travestis. As travestis que são historicamente estigmatizadas e marginalizadas não conseguem, na maioria dos casos, empregos ditos como formais e acabam adentrando o mundo da prostituição (BENEDETTI, 2005).

A prostituição requer fundamentalmente um olhar atento no que tange a saúde, visto que as pessoas que trabalham no mercado do sexo estão vulneráveis a diversos fatores de risco que o ambiente que vivem a integram, como o risco de sofrerem violência de genêro durante a sua atuação neste mercado, as violências que a própria sociedade aplica sobre as trabalhadoras e trabalhadores noturnos é o principal fator que denota essas vulnerabilidades (BENEDETTI, 2005; BRITO et al., 2010).

A travesti que é uma das figuras mais estigmatizadas da comunidade de Lésbicas, Gays, Bissexuais, Travestis e Transexuais (LGBT) se vêm sem fuga ao trabalho como profissional do sexo, visto que as mesmas por serem seres que transitam entre os gêneros, e são como todas as outras pessoas, dependem da mesma maneira que o restante da sociedade de alguma forma de sustento para elas, assim a prostituição parece ser um caminho rápido e fácil para a aquisição de recursos para a sobrevivência (BENEDETTI, 2005).

As travestis, que são seres que transitam entre os sexos, que anteriormente não eram tão bem definidos e facilmente explicados, geram este desconforto visual e se torna presunçoso dizer que são vistas com naturalidade pela sociedade que é e foi acostumada com estes dois sexos, onde a heteronormatividade é compulsória (BOHM, 2009).

Anteriormente, as travestis tinham uma representação de monstruosidade, onde elas não eram normais e assim, deveriam ser consideradas como anormais. As representações patológicas que eram vinculadas as travestis as faziam serem identificadas como seres impuros, sem definição e que não sabiam ao certo como, ou o que, queriam ser (BRAGA, 2011). 
A transfobia então tem inicio neste ponto, onde o que não se é normal, o que causa estranhamento ou desconforto, deve ser afastado, retirado de vista e colocado longe do alcance das demais pessoas, pois a doença de ser travesti poderia ser disseminada (JESUS, 2014).

As invisibilidades das travestis também se deram pelo fato de nos anos 60 e 70, os movimentos feministas, gays e lésbicos ofuscaram as outras camadas mais vulneráveis de sexo e identidades sexuais e de gênero. Onde ficou ainda mais obscuro o mundo que viviam as travestis, transexuais, bissexuais e as demais sexualidades e gêneros. As autoras Beauvoir (1949) e Scott (2016), apontavam para uma crescente definição de construção de gênero na sociedade e o que estes gêneros poderiam contribuir para o meio que estavam inseridos, sendo observados os gêneros transitórios entre o binarismo conhecido (FERREIRA, 2014).

A travesti trabalhadora do sexo requer um cuidado com a saúde muito específico, devido as suas vunerabildiades. A saúde do trabalhador e da trabalhadora teve inicio de discussões e aprimoramento científico somente nas décadas de 30 até 80 , a regulamentação e as condições do ambiente de trabalho e das atividades excercidas pelo trabalhador eram atribuições do Ministério do Trabalho. O cuidado com a saúde destes trabalhadores de forma geral na saúde pública se dá no Brasil em meados dos anos 80 do século passado (LACAZ, 1996).

A obrigatoriedade do cuidado com o trabalhador brasileiro se deu após a assembleia constituinte de 1988, onde nela as atribuições legais para a criação do Sistema Único de Saúde (SUS) foram inseridas, e com essa criação a Saúde do Trabalhador se torna obrigação da União. Assim, após a criação do SUS foram inseridos programas de saúde publica para priorizar a saúde dos trabalhadores (BRASIL, 1988).

Com o passar dos anos e discussões no que tange a Saúde do Trabalhador em 2012 foi instituída a Política Nacional de Saúde do Trabalhador e da Trabalhadora (PNSTT), onde nela vislumbra em seus artigos a finalidade de definir princípios e diretrizes para que o governo, de 
forma tripartite (União, Estados e Municípios), que gerem o SUS, possa fomentar a Saúde do Trabalhador. Fazendo o papel de vigilância em saúde, para que aconteça a promoção, proteção e prevenção da saúde de todos os trabalhadores brasileiros, diminuindo a morbimortalidade decorrentes do ambiente de trabalho (BRASIL, 2012).

Assim, o presente estudo tem como uma de suas finalidades adentrar e conhecer melhor as realidades que as travestis profissionais do sexo vivenciam, para apontar a violência sofrida no ambiente de trabalho do mereado do-sexo, visto principalmente pela escassa literatura brasileira que vislumbra o assunto.

\section{Objetivos}

Caracterizar as condições socioeconômicas de travestis profissionais do sexo.

\section{Materiais e Métodos}

Um estudo tranversal, descritivo, de caráter quantitativo. A população do estudo foi constituída por 46 travestis profissionais do sexo da cidade de Uberlândia-MG, Brasil. A população se constituiu pelas travestis participantes da "Rede Nacional de Pessoas Trans do Brasil" que tem como profissão a prostituição. Que tenham idade superior à 18 anos, que trabalhem como profissionais do sexo.

O projeto foi submetido ao CEP (Comitê de Ética e Pesquisa) da Universidade Federal de Uberlândia, de acordo com a Resolução 466/12, aprovado com o parecer de número: 1.864 .944

A coleta de entrevistas ocorrerá em local e horário a ser pactuado com as profissionais do sexo afim de não atrapalhar sua rotina e trabalho. Preferencialmente, a coleta ocorrerá em sala reservada no Rede Nacional de Pessoas Trans do Brasil, e se preferirem no próprio local de serviço, fora do seu horário de expediente. Foram aplicados questionários de Caracterização 
de Informações Socioeconômicas e um roteiro sobre a violência no ambiente de trabalho.

\section{Resultados e Discussões}

$\mathrm{Na}$ Tabela 1 descritos os dados Socioeconômicos, podemos observar que 39 entrevistadas afirmam ser solteiras o que equivale a $84,4 \%$ do $n$ total de 46, apenas 4 delas são casadas. A maioria das entrevistadas (41,3\%) são da etnia parda, havendo apenas 4 amarelas/orientais. 100\% delas são alfabetizadas, porém nenhuma delas com ensino superior completo e a maior parcela delas têm o ensino médio completo $(34,8 \%)$ somando um $n$ de 16. Um total de 45,6\% ( $n=21)$ das entrevistadas mora em outro tipo de habitação, o que se pode afirmar que moram pensão/pensionato após a pesquisa de campo.

A faixa etária das entrevistadas é entre os 18 e 44 anos, sendo a idade média delas de 24 anos. Ao se tratar de renda, pode se afirmar que a renda média é de $\mathrm{R} \$ 2.876,09$, sendo que o valor maior de recebimento mensal afirmado por elas é de $\mathrm{R} \$ 10.000,00$ e o mais baixo de $\mathrm{R} \$ 900,00$.

Tabela 1 - Dados Socioeconômicos - Uberlândia - MG

\begin{tabular}{c|cccc}
\hline \hline Pergunta & Resposta & N & \% & N total \\
\hline \multirow{2}{*}{ Estado Civil } & Solteira & 39 & 84,8 & \\
& Casada & 4 & 8,7 & 46 \\
& União Estável & 3 & 6,5 & \\
\hline \multirow{2}{*}{ Etnia } & Branca/caucasiana & 10 & 21,7 & \\
& Negra & 13 & 28,3 & \\
& Parda & 19 & 41,3 & \\
& Amarela/oriental & 4 & 8,7 & \\
\hline \multirow{2}{*}{ Alfabetizada } & Sim & 46 & 100 & \\
& Não & 0 & 0 & \\
\hline
\end{tabular}




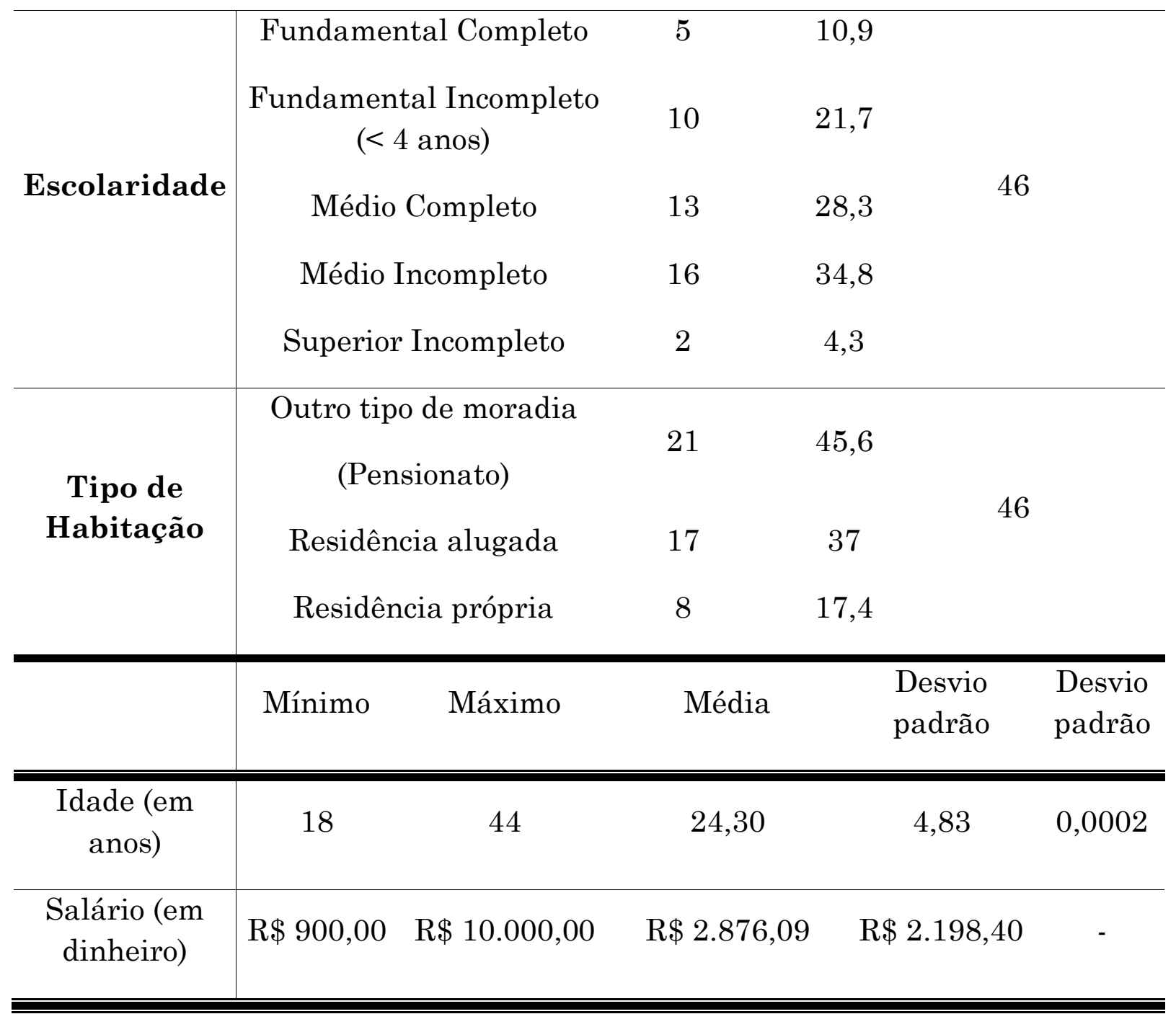

Fonte: os autores, 2018.

No estudo de Ferraz e outros autores (2006) desenvolvido aqui na cidade de Uberlândia - MG no ano de 2004, podemos observar que $71 \%$ das entrevistadas se diziam sem relação fixas (podendo entender que são solteiras), indo de encontro com os dados de nossa pesquisa (84,8\%), se mostrando um valor superior, porém onde podemos ver, que mesmo após 14 anos, o perfil do estado civil das travestis profissionais do sexo permanecem majoritariamente delas estando solteiras.

Da mesma maneira que no presente estudo, outros trabalhos publicados em periódicos mostram que majoritariamente das travestis são solteiras, como apontam nos estudos de Silva e outros autores (2016), que $68,75 \%$ da entrevistadas se dizem solteiras e o estudo de Costa e demais autores (2018), mostra que 75,1\% das suas entrevistadas também não estão em uniões estáveis ou outros tipos de relacionamentos. Assim, a literatura 
vai de encontro com o presente trabalho, das nossas entrevistadas se declararam solteiras. Há uma escassez de publicações internacionais que detalham sobre Estado Civil de travestis.

Em estudos conduzidos nos Estados Unidos da América (EUA), realizados no final do século 20 em Atlanta no estado da Geórgia, aponta que $80 \%$ das entrevistadas se consideravam negras e em outro estudo $83 \%$ também se considera da etnia negra (ELFISON et al., 1993; BOLES; ELFISON, 1994). Mostrando um perfil diferente dos dados coletados atualmente, onde em um estudo elaborado atualmente, aponta que 56,2\% das entrevistadas se consideram Afro Americanas (KENAGY; HSIEH, 2014).

Assim, podemos observar que comparados a estudos as entrevistadas neste trabalho se consideram, em sua maioria, negras ou pardas, sendo 32 , ou seja, $69,6 \%$ das entrevistadas, no estudo de Ferraz e demais colaboradores (2006), observamos que este número é inferior, sendo 45\% das entrevistadas se declararão não brancas (pertencentes a outras raças), caracterizando uma mudança no perfil étnico das profissionais do sexo do munícipio.

Em um estudo na região metropolitana de Recife em 2013, este número é superior, tendo como 78,2\% das 110 travestis entrevistadas se considerando da mesma etnia (SOUSA; FERREIRA; SÁ, 2013). Em outro de uma cidade do interior do nordeste brasileiro, o número de entrevistadas que fazem parte deste mesmo grupo étnico, é de 93,75\%, em um total de 16 entrevistadas (SILVA et al., 2016). Em outro estudo parecido na cidade de São Paulo, onde foi respondida a questão etnia com apenas duas opções de respostas, se a entrevistada se considerava branca ou não branca do número total de 58 entrevistadas, 66,5\% não se consideravam branca (FERREIRA; FRANCISCO; NOGUEIRA, 2016).

Já em um estudo respondido por forma de questionário eletrônico, por livre demanda e disponibilidade, foram realizadas 337 entrevistas com travestis e transexuais do estado de São Paulo e Rio Grande do Sul, sendo 
que $27,9 \%$ se consideravam, negras, pardas ou de origem indígena (COSTA, 2018).

Podemos observar assim, que o perfil das travestis norte americanas é diferente do perfil das entrevistadas brasileiras. Com estas comparações podemos observar e questionar se, também no universo de travestis e transexuais, o privilégio de acesso à internet se faz, majoritariamente, entre pessoas brancas. Ou se regiões consideradas desenvolvidas economicamente e socialmente, como a região Sul e Sudeste brasileira, pode ser então consideradas que a maior parcela de travestis e transexuais brancas está presentes nestes estados, o que pode mostrar que centros econômicos são locais que a presença de travestis brancas são mais aceitas que em regiões mais pobres e menos desenvolvidas.

Ao compararmos o nível de escolaridade das travestis deste estudo com os dados da Pesquisa Nacional de Amostra por Domicílios (PNAD), em 2013, detalhou-se aqui que nenhuma das entrevistadas é analfabeta, diferente das taxas da população brasileira geral que é de $8,3 \%$. A taxa de analfabetismo funcional (menos que quatro anos de estudo) no Brasil é de $17,8 \%$ contra os $21,7 \%(n=10)$ em nossa pesquisa (IBGE, 2015). Em um estudo conduzido neste mesmo município, 14 anos atrás, foi destacada uma taxa de analfabetismo de 4\% das entrevistadas (FERRAZ et al., 2006).

A taxa de analfabetismo da pesquisa elaborada por Sousa, Ferreira e Sá (2013), foi de 9,2\%, dado superior a do nosso estudo, porém a taxa de analfabetismo funcional é de $17,4 \%$, ficando abaixo da destacada pela nossa pesquisa.

Em outro trabalho o presente estudo vai de encontro com este trabalho, onde apresenta 100\% das suas entrevistadas alfabetizadas ou que frequentaram, em algum momento da vida, instituições de ensino, não detalhando a taxa de analfabetismo funcional (SILVA et al., 2016).

No trabalho de Ferreira, Francisco e Nogueira (2016), foi apresentada uma taxa de analfabetismo de $3,5 \%$ de travestis entrevistadas da cidade de 
São Paulo, e uma taxa de 13,8\% de analfabetismo funcional, que é inferior a média nacional e os valores de nosso trabalho.

Em um estudo conduzido com travestis brasileiras, também em São Paulo capital, foi observado que 97,9\% das entrevistadas são alfabetizadas e o restante nunca participou de nenhuma alfabetização, porém aponta para uma taxa de analfabetismo funcional menor que o de nossa pesquisa, que alcança apenas 9,5\% das participantes, inferior ao de nossa pesquisa (COSTA et al., 2018).

Em um trabalho desenvolvido na Filadélfia nos EUA, foi visto que 100\% das travestis frequentaram o ensino médio ou High School, como é chamado lá, e 7,1\% das entrevistadas frequentavam ou frequentam, algum tipo de estudo pós formatura do ensino médio. Essa realidade se torna muito diferente da que enfrentamos aqui no Brasil (KENAGY. HSIEH, 2014).

As escolas no Brasil seguem modelos e diretrizes que não incluem as diversidades de gêneros e suas expressões de sexualidades individuais, focado em modelos heteronormativos e convencionais, se tornam um ambiente expulsivo para travestis que desejam ingressar na vida escolar, possibilitando então que essas populações se tornem menos capacitadas, no que tange educação, e assim propiciando a marginalização e vulnerabilidades. Ambientes que eram para serem acolhedores tornam-se pesadelos no cotidiano de travestis (PERES, 2009; CRUZ, 2011).

No que tange o tipo de moradia das entrevistadas, foi visto que 45,6\% $(n=21)$ moram em casas que são destinadas para o convívio próprio entre elas, são conhecidos como pensões ou pensionatos, locais onde elas podem expressar suas identidades de gênero, sua feminilidade e viver com pessoas iguais a elas, ou seja, travestis profissionais do sexo. Estes locais se tornam além de um local de preparação para enfrentar a rua ou sendo um local para ir de encontro com os clientes, são os locais que elas têm como referencia de lar, podendo se apoiar e mostrar a feminilidade, que no cotidiano, no seio familiar ou nas ruas, são impedidas ou estigmatizadas. 
Este número de travestis que vivem nestes locais, se demonstrou superior ao ser comparado com profissionais do sexo cisgênero que vivem em locais que são as casas de encontro, onde no estudo de Salmeron e Pessoa (2012), desenvolvido na cidade de São Paulo, aponta que 26\% das suas profissionais do sexo participantes da pesquisa vivem nestas condições, em nossa pesquisa, 37\% $(\mathrm{n}=17)$ vivem em residência alugadas, em contra partida $18 \%$ das entrevistadas da pesquisa supracitada, moram nas mesmas condições e na nossa pesquisa 8 entrevistadas $(17,4 \%)$ vivem em casa própria, valor próximo ao comparado com as prostitutas cis que são de $18 \%$.

Em outro trabalho conduzido na cidade de São Paulo, foi questionado se a travesti entrevistada vivia em situação de rua ou não, onde 25,9\% delas afirmaram que vive nesta condição, uma realidade muito diferente da observado neste estudo, onde nenhuma delas afirmou viver desta maneira (FERREIRA; FRANCISCO; NOGUEIRA, 2016).

Em outro estudo, desenvolvido na cidade de São Francisco nos EUA, feito com MtF, foi visto que 5\% das entrevistas vivem nas ruas da cidade, e o restante vivem em casas temporárias $(n=46 \%)$ e ou em casas permanentes $(\mathrm{n}=49 \%)$. Esta realidade de pessoas que vivem nas ruas não está distante da realidade das travestis que responderam a nossa pesquisa, pois algumas estavam vivem no pensionato, por terem sido abandonadas pelos familiares, assim para não viverem em situação de rua, optam por estarem unidas (NEMOTO et al., 2004).

A média de idade das profissionais do sexo do presente estudo é de 24,3 anos (Desvio padrão= 4,8), ao observarmos o estudo conduzido também aqui na cidade de Uberlândia, no ano de 2004 a idade média das entrevistadas era de 26 anos, observamos uma diminuição desta idade em 14 anos (FERRAZ et al., 2006). Na região metropolitana de Recife, percebemos que as travestis entrevistadas lá, têm uma média de idade de 28,3 anos, ou seja, 4 anos a mais que as deste estudo (SOUSA; FERREIRA; SÁ, 2012). Em outro estudo feito no nordeste brasileiro, a média de idade das entrevistadas foi de 23,5 anos, sendo 0,8 anos mais novas que as apontadas neste estudo (SILVA et al., 2016). 
Em estudos feitos nos EUA, um na cidade de São Francisco, as entrevistadas de lá apresentam um idade média de 34 anos, sendo, em média, 10 anos mais velhas do que as do Brasil (NEMOTO et al., 2004) outro elaborado em Atlanta, no início dos anos 90 do século passado, foi de 25 anos, sendo superior à média aqui do presente estudo (ELIFSON et al., 1993).

Isso se faz notar que as travestis que não residem no Brasil podem viver mais, pois aqui é o país que mais mata travestis e transexuais do planeta, sendo a expectativa de vida delas de 30 anos (ANTRA, 2015 apud DA SILVA; MAIO, 2017; NOGUEIRA; AQUINO; CABRAL, 2017).

A renda mensal das entrevistadas média das entrevistadas é de 2.876 reais, sendo pouco mais que 3 salário mínimos de acordo com o valor atual que é de 954 reais, onde no município de Uberlândia (local da pesquisa) o salário médio mensal dos trabalhadores formais é de 2,6 salários. Assim, podemos observar que o emprego informal da prostituição, está acima da média salarial do munícipio do estudo (IBGE, 2016; BRITO, 2018).

No estudo de Ferraz e demais colaboradores (2006), foi visto que neste município, no ano de 2004 a maioria das entrevistas (52\%) tinham uma média salarial de 1 até 3 salários mínimos, não sendo diferente da realidade que encontramos atualmente.

No estudo feito em São Francisco no EUA, a média salarial das MtF que estão ou não na prostituição, é na maioria das entrevistadas ( $\mathrm{n}=34 \%)$ de 500 a 999 dólares, sendo este valor de acordo com a cotação do dólar atual $(3,755$ reais) de 1877 reais até 3.751 reais, sendo superior a renda vista do presente estudo (NEMOTO et al., 2004; UOL, 2018).

Em outro estudo feito em Chicago e Filadélfia nos EUA, foi visto que o valor anual que as MtF entrevistadas ganhavam era superior a 40 mil dólares, equivalendo assim há, em média 3.340 dólares mensais, convertendo esse valor, se aproxima aos 12.500 reais por mês. Um valor muito elevado comparado à média das entrevistadas neste estudo (KENAGY; HSIEH, 2010; UOL, 2018). 
Tabela 2. Violência no Ambiente de Trabalho-Uberlândia-MG

\begin{tabular}{|c|c|c|c|}
\hline Perguntas & Resposta & $\mathbf{N}$ & $\%$ \\
\hline Você já sofreu violência física? & $\begin{array}{l}\text { Sim } \\
\text { Não }\end{array}$ & $\begin{array}{l}21 \\
25\end{array}$ & $\begin{array}{l}45,7 \\
54,3\end{array}$ \\
\hline Você já sofreu violência verbal? & $\begin{array}{l}\text { Sim } \\
\text { Nã }\end{array}$ & $\begin{array}{l}30 \\
16\end{array}$ & $\begin{array}{l}65,2 \\
34,8\end{array}$ \\
\hline Você já sofreu violência sexual? & $\begin{array}{l}\text { Sim } \\
\text { Não }\end{array}$ & $\begin{array}{l}11 \\
35\end{array}$ & $\begin{array}{l}23,9 \\
76,1\end{array}$ \\
\hline $\begin{array}{l}\text { Você fez algum tipo de } \\
\text { queixa/denuncia sobre a violência } \\
\text { que sofreu? }\end{array}$ & $\begin{array}{l}\text { Sim } \\
\text { Não }\end{array}$ & $\begin{array}{l}10 \\
\mathbf{3 6}\end{array}$ & $\begin{array}{l}21,7 \\
78,3\end{array}$ \\
\hline
\end{tabular}

Fonte: os autores, 2018.

$\mathrm{Na}$ tabela 2 , estão associados os dados entre as variáveis numéricas socioeconômicas e violência no ambiente de trabalho. Onde podemos ebservar que a média é de 23 (valor $p=0,028$ ) anos das travestis que sofreram violência sexual no ambiente de trabalho e que a idade média das que fizeram denuncia sobre algum tipo de violência é de 21,4 anos (valor $p=$ $0,016)$.

\section{Considerações finais}

Devido ao contexto que as travestis profissionais do sexo vivem, percebemos que há um grande descaso por meio de políticas públicas voltadas ao atendimento a essa população. Que a despatologização ainda é inexistente dentro de instituições que deveriam ser locais de refúgio para este grupo.

As condições de vida, a baixa renda e a baixa escolaridade, as deixam fora do mercado de trabalho formal, mesmo quando se há o mínimo de condição para frequentar ambientes de saudáveis, realizar atividades laborais dita como normais, as travestis são excluídas. 
Devido estes fatores supracitados, e as necessidades de vida dirária as travestis pelos estigmas que vivenciam cotidianamente encontram na prostituição um local para se expressarem no que tange a feminilidade, sempre em construção, dos seus corpos. Em contra partida este ambiente as deixam ainda mais vulneráveis a violências.

Essa exclusão histórica se torna o que chamamos de estigmatização, que mesmo após anos de luta ainda existe dentro da realidade dete grupo. Como podemos perceber com o passar do tempo a violência se tornou o costume e uma realidade na vida delas.

Não há mais motivação nem para realizar as denuncias sobre as violências sofridas. Isso é extremamente degradante, o local onde elas teriam como um porto seguro também é um ambiente que as silenciam e não deixam ter espaço.

O se sentir mulher é uma pratica diária das travestis, que, por vezes, abrem mão de viver em sociedade, serem encaradas como normais ou que se encaixam dentro de algum padrão estabelecido ou previamente aceito, assim, ser travesti acima de tudo é um ato de resistência

\section{Referências}

KOWARICK, L. Trabalho e vadiagem: a origem do trabalho livre no Brasil. Editora Brasiliense, 1987.

LACAZ, F.A.C. O campo Saúde do Trabalhador: resgatando conhecimentos e práticas sobre as relações trabalho-saúde. Cadernos de Saúde Pública, v. 23, p. 757-766, 2007.

BASTOS, M.C. Trabalho formal e informal. Trabalho formal e informal, 2004.

BRASIL. Ministério da Saúde (MS). Conselho Nacional de Combate à Discriminação. Brasil Sem Homofobia: Programa de combate à violência e à discriminação contra GLTB e promoção da cidadania homossexual. Brasília, DF, 2004. 
BENEDETTI, M.R. Toda feita: o corpo e o gênero das travestis. Rio de Janeiro: Garamond, 2005.

BRITO, C.R.S. et al. Ajudando a curar o preconceito: nossos desafios na implantação do ambulatório "Saúde das Travestis" na cidade de UberlândiaMG. Revista de Educação Popular, v. 8, n. 1, 2010.

BOHM, A.M. Os' Monstros'e a Escola: identidade e escolaridade de sujeitos travestis. 2009.

BRAGA, S. O outro corpo do (eu): a discursividade na carne. Revista do GEL, v. 8, n. 1, p. 138-155, 2011.

JESUS, J.G. Transfobia e crimes de ódio: assassinatos de pessoas transgênero como genocídio. História Ágora, 2014.

FERREIRA, G.G. Travestis e prisões: a experiência social e a materialidade do sexo e do gênero sob o lusco-fusco do cárcere. 2014. Dissertação de Mestrado. Pontifícia Universidade Católica do Rio Grande do Sul.

LACAZ, F.A.C. et al. Saúde do Trabalhador: um estudo sobre as formações discursivas da academia dos serviços e do movimento sindical. 1996.

BRASIL, Constituição Federal. Constituição federal. São Paulo: Revista dos Tribunais, 1988.

BRASIL. Ministério da Saúde (MS). Portaria n. 1.823, de 23 de agosto de 2012. Institui a Política Nacional de Saúde do Trabalhador e da Trabalhadora. 2012.

ELIFSON, K. W.; Boles, J., Posey; E., Sweat, M.; Darrow, W.; Elsea, W. Male transvestite prostitutes and HIV risk. American Journal of Public Health, v. 83, n. 2, p. 260-262, 1993.

BOLES, J.; ELIFSON, K.W.; SWEAT, M. Risk factors associated with HIV infection among male prostitutes. American Journal of Public Health, v. 83, n. 1, p. 79-83, 1994.

KENAGY, G.P.; HSIEH, C-M. Measuring quality of life: A case for reexamining the assessment of domain importance weighting. Applied Research in Quality of Life, v. 9, n. 1, p. 63-77, 2014.

SOUSA, P.J.; FERREIRA, L.O.C.; SÁ, J.B. Estudo descritivo da homofobia e vulnerabilidade ao HIV/Aids das travestis da Região Metropolitana do Recife, Brasil. Ciência \& Saúde Coletiva, v. 18, p. 2239-2251, 2013. 
SILVA, G.W.S; SOUZA, E.F L.; SENA, R.C.F.D.; MOURA, I. B. D. L., SOBREIRA, M.V.S.; MIRANDA, F.A.N.D.. Situações de violência contra travestis e transexuais em um município do nordeste brasileiro. Revista Gaúcha de Enfermagem, v. 37, n. 2, 2016.

FERREIRA Jr., S.; FRANCISCO, P.M.S.B.; NOGUEIRA, P.A.. Perfil de travestis e transgêneros: tuberculose e HIV/Aids na cidade de São Paulo. Revista Panamericana de Salud Pública, v. 40, p. 410-417, 2016.

COSTA, A.B. Vulnerabilidade para o HIV em mulheres trans: o papel da psicologia e o acesso à saúde. 2015.

IBGE.Censo Demográfico 2014. Disponível em https://www.ibge.gov.br/. Acesso em: 2017.

IBGE. Pesquisa Nacional por Amostra de Domicílios (PNAD) 2014. Disponível em:

https://biblioteca.ibge.gov.br/visualizacao/livros/liv94935.pdf/. Acesso em: 2017.

FERRAZ E.A.F.; SOUZA C.; SOUZA L.M.; COSTA N. Travestis profissionais do sexo e HIV/AIDS: conhecimento, opiniões e atitudes. [Trabalho apresentado no Seminário de Diamantina; 2006; Diamantina, $\mathrm{BR}]$.

DA SILVA JUNIOR, J.A. Direitos à meia luz: regulamentação do uso do nome social de estudantes travestis e transexuais nas instituições escolares. Revista da FAEEBA-Educação e Contemporaneidade, v. 25, n. 45, 2016.

CRUZ, E.F. Banheiros, travestis, relações de gênero e diferenças no cotidiano escolar. Rev Psicol Polít. 2011;11(21):73-90.

PERES, W.S. Cenas de Exclusões Anunciadas: travestis, transexuais, transgêneros e a escola brasileira. In: Junqueira RD, organizador. Diversidade Sexual na Educação: problematizações sobre a homofobia nas escolas. Brasília: Ministério da Educação, Secretaria de Educação Continuada, Alfabetização e Diversidade, UNESCO; 2009. p. 235323.

NEMOTO, T., SAUSA, L. A., OPERARIO, D., KEATLY, J. (2006). Need for HIV/AIDS education and intervention for MTF transgenders: responding to the challenge. Journal of Homosexuality, 51(1), 183-201.

BARBOSA, B. R. S. N. Vida e morte (in) visíveis: Notas sobre o Feminicídio e sua Aplicabilidade para Mulheres Transexuais e Travestis. Alethes, Juiz de Fora, n.9, p. 162-172, 2015. 
NOGUEIRA, S. N. B.; AQUINO, T. A.; CABRAL, E. A. Dossiê: a geografia dos corpos das pessoas trans. Rede Trans Brasil, 2017.

Site Trip transformadores (2012). Entrevista com Gabriela Leite. Disponível em:

$<$ http://revistatrip.uol.com.br/transformadores/site/homenageados/index.php ?cod=93>. Acesso em: 24 ago. 2017.

Recebido em novembro de 2018. Aprovado em novembro de 2018. 